\title{
Study on Pricing Mechanism of Urban Public Service Based on Viewpoint of Performance Evaluation
}

\author{
Leping Zhang ${ }^{1}$ \\ ${ }^{1}$ School of Business and Management, Donghua University, Shanghai, China \\ Correspondence: Zhang Leping. E-mail: sanlucky@163.com
}

Received: September 11, 2017

Accepted: October 13, 2017

Online Published: October 28, 2017

doi:10.5539/ass.v13n11p117

URL: https://doi.org/10.5539/ass.v13n11p117

\begin{abstract}
Pricing mechanism and price supervision are the most important way to supervise the filed of public service. This paper studies the pricing methods and principles of Chinese public service product based on performance evaluation theory of public service, and compares the different methods of the urban public service pricing among various countries, then analyze the problems of the current pricing mechanism of Chinese urban public service product, and finally contribute suggestion to improve the pricing mechanism of Chinese urban public service product
\end{abstract}

Keywords: Public Service, Pricing Mechanism, Performance Evaluation

\section{Introduction}

The supply of urban public service product effects the daily lives of every family and the whole city, which includes the investment and management of the facilities of water, power, heat, gas, public traffic, communication, post, waste exhaust, rubbish treatment, etc. For a long time, worldwide government-owned enterprises have monopolized the supply of the public service and products. Government-owned enterprises concern politics and neglect cost and benefit, so they have a lot of problems such as lower production efficiency, serious resource waste, worse service quality, no profit, complain by people, etc.

Since 1980s, the theory of "new public management" has been accepted by European and American. A lot of government functions have been transferred to public service enterprises, who provides public products and service. More and more cities try to introduce the tool of "performance evaluation" into the pricing of public service and product, which includes indexes like economic, efficiency, effectiveness, quality, equity, responsibility and response.

\section{Public service pricing and performance evaluation}

\section{1 pricing principle and performance evaluation}

The pricing of urban public service is mostly diversified by five principles, which have close relationship with performance evaluation indexes of efficiency, effectiveness, quality and responsibility.

1) Economic efficiency. To optimize resource use by reasonable pricing is very important. High pricing will reduce usage of common user and cause overcapacity. Meanwhile, low-income people can not afford necessary public service. On the contrary, low pricing will lead to waste of resource.

2) Commonweal Character. Public service should maximize the public benefit of the whole people, so its pricing have to consider the difference of people's income. Usually, we offer allowance to low-income people and request high-consumption people to pay more by progression. We have to keep balance between equity and efficiency accordingly.

3) Reasonable profit. As a company, city public service enterprise must consider the balance of income and cost. Without profit, the enterprise can not expand its reproduction and improve public service. And then, people are not willing to pay money for worse service. It will lead to a vicious circle.

4) Public satisfaction. When we make pricing of city public service, we must consider social effects. The process of pricing decision should be supervised by the people. It's a good way to invite common people to anticipate the whole process of pricing and express different ideas. 
5) Feasibility. The pricing of public service should be easy to operate. Some pricing system is too complex, and we have to pay additional cost to collect the money. It should be designed much more reasonable and convenient.

\subsection{Various pricing supervision and performance evaluation}

In the world, there are two mainstream methods: price supervision and cost supervision. Different methods of pricing supervision are based on different indexes of public service performance evaluation. Some of them concern social performance, some concern financial performance and the others concern both.

\subsubsection{Price Supervision}

In UK, government set an upper-limit for public service price. Price increasing index of public service products can not be more than the difference value between RPI (Retail Price Index) and industrial economic efficiency. It's no necessary for government to monitor the operation cost of public service. Based on social performance evaluation, UK government focuses on social benefits and social equity to consider the acceptance capacity for currency inflation.

In France, franchise is the most popular to supervise the pricing of urban public service. Government usually authorize the third-party organization to calculate the price of a kind of public service produce, considering the balance between incomes and expenses, the volume of production and consumption, the change of business pattern, tax and others. The calculated price should be discussed and confirmed by the congress, who audits the public service price and enterprise income regularly. It will be solved by the special arbitration organization when people think the pricing is not reasonable. French government supervise financial operation capacity of public service enterprise and emphasis the economic benefits of enterprise, based on financial performance evaluation.

In USA, government usually set up price adjustment funds of urban public service. During the process of price adjustment, they consider factors such as the benefit of operation enterprise, the overall acceptability of society, the influence to economic growth, the rationality of adjustment and the openness of the price adjustment measures. Based on the comprehensive performance evaluation, enterprises of USA keep balance well among the economic benefits, operational efficiency and social benefits.

\subsubsection{Cost Supervision}

In China, cost supervision is mainly used by government currently. The government confirm price through monitoring and auditing the cost of productive operation of public service enterprises periodically. The government requests enterprises to set up normal financial management regulation and support the government to audit the operation cost. However, in fact, it's difficult for the government to obtain the real data of enterprise cost, because of information asymmetry.

\subsection{Pricing method and performance evaluation}

The pricing of urban public service depends on the influence of both pricing principle and pricing method. Usually, there are three popular pricing methods, such as average cost pricing, two-parts pricing and differential pricing. Average pricing can approach maximized economic welfare based on balance of payments for enterprise Two-parts pricing is combined by two parts of cost, including monthly or annual expense and expense related with usage. Differential pricing means that making different price according to different time or period.

The selection of pricing method is influenced by the government's financial situation, different industry characteristics, consumer economic status, supply and demand, resource scarcity, etc. Different pricing methods have different concern on economic benefits and social benefits, which also lead to different index results of performance evaluation.

\subsection{Price hearing system and performance evaluation}

The hearing system is widely applied in western countries, and also used in China sometimes. Based on pricing hearings, the people can directly anticipate deciding price of urban public service, which can avoid monopolistic price growth and improve social performance and public satisfaction obviously.

\section{Problems of current pricing mechanism of Chinese urban public service}

Currently, Chinese urban public service enterprises make pricing according to "cost plus reasonable profit". Policy-related losses become the best excuse for public service enterprises to face government and social public. Without effective supervision, the enterprises have no pressure and enthusiasm to control operation cost, which lead to high profit of urban public service enterprises and low satisfaction of the public. 
Furthermore, some other problems of urban public service need to be solved in China urgently, which effects rationality and validity of public service pricing. Firstly, the government plays two roles of price maker and price supervisor, just like one person with two roles of both athlete and referee. It will bring to lower operation efficiency and lower commonweal. Secondly, the hearing procedure has doubted by people as the price always goes up after price hearing. Thirdly, power corruption still happens during price supervision in China.

To solve above problem, several measures should be taken in the coming days. First of all, it's urgent to set up the complete law system for pricing of public service. Secondly, technical tools like internet and big data can be applied to encourage people to anticipate the pricing hearing to ensure acceptable pricing. Thirdly, third-party audit organization should be introduced into price supervision to avoid power corruption.

\section{Conclusion}

In a word, from the viewpoint of performance evaluation, Chinese public service has made obvious progress in pricing mechanism, pricing supervision and pricing hearing system, but still has a long way to go.

\section{References}

Zeng Jun. (2006). New theory of public management. Beijing, China: People's Publishing House.

Zhuo Yue. (2011). Performance evaluation of public department. Beijing, China: China Remin University Press.

Song Pingping \& Sun Hao. (2009). New research on public service pricing. Wuhan, China: Contemporary Economics, 2009(8):150-151.

Liu Jingai \& Tao Chuanping. (2012). Introduction to public enterprise management. Jinan, China: Shandong People's Publishing House.

Miao Jingli. (2011). Public Enterprise Management. Northeast University of Finance and Economics Press.

Hu Wei \& Wu Wei. (2013). Blue book on public satisfaction of public service in Chinese cities. Shanghai, China: Shanghai People's Publishing House.

Zhong Jun \& Wu Zhenggao. (2013). Blue book on evaluation for Chinese urban basic public service (2012 2013) . Beijing, China: Social Sciences Literature Publishing House.

Wang Hailing. (2002). Price Management of Public Enterprise in Western. Nanchang, China: Prices Monthly, 2002(5).

\section{Copyrights}

Copyright for this article is retained by the author(s), with first publication rights granted to the journal.

This is an open-access article distributed under the terms and conditions of the Creative Commons Attribution license (http://creativecommons.org/licenses/by/4.0/). 